\title{
O EQUILIBRIO BIOLÓGICO NA ETIOLOGIA DO IMPALUDISMO (1)
}

por E. ROUBAUD, Instituto Pasteur, Paris.

As oscilações naturais do estado palustre numa determinada região, resultam do conflito entre os fatôres favoraveis e os fatôres contrários ao cíclo plasmodico. Quando essas influências tendem a equilibrar-se, o .estado palustre estabilisa-se em um minimo. Êsse estado de equilibrio deve aparecer-nos como uma resultante do conflito das mais complexas intervenções biológicas. Há já muito tempo que se vem encarando, nessa ordem de idéias, as relações numéricas simples entre os diversos elementos principais do problema: o homem, o virus e o anófeles. Muitas vêses foi dito, por exemplo, que a curva epidemiológica é, antes de mais nada, influenciada pelo numero relativo dos habitantes de uma região palustre e o dos mosquitos. Ross formulou leis numéricas, validas para condições fixadas de populações humanas e anofelinicas, que traduzem um certo estado de equilibrio entre os 'diferentes fatôres etiológicos. Quando qualquer um dos componentes do fatôr equilibrio é modificado no seu valor numérico relativo, quer se trate do homem, do virus ou do mosquito, as condições de infecção humana global tambem se moḍificam.

Essas noções gerais estão bem estabelecidas e me parece desnecessário voltar a elas. Porém quando procuramos definir, em detalhe a proteção humana, tropeçamos em dificuldades particulares. $\mathrm{Si}$, sob o ponto de vista humano, as condições que intervêm são relativamente bem conhecidas, aquelas que regem o dominio biológico do mosquito o são bastante menos. Aqui desejo simplesmente resaltar por alguns exemplos, quanto o problema, encarado unicamente sob o ponto de vista do anofelino, deve parecer-nos complexo. As influências biológicas às quais os mosquitos reagem, e que são susceptiveis de trazer elementos de notória perturbação ao equilibrio considerado, são muito mais diversas e muito mais dificeis de interpretar do que geralmente se pensa.

Efetivamente, não é apenas o numero absoluto dos anofelinos, que merece entrar em linha de conta nas previsões de sua possivel intervenção como vetôres de infecção; são essencialmente as multiplas influências que tornam mais ou menos estreitas e continuas suas relações com o homem.

Quando as influências biológicas que regem os contactos se equilibram, num sentido que as reduz a um minimo, a proteção humana está mais ou menos assegurada; mas qualquer modificação biológica, de natureza a fazer mais frequentes e mais prolongadas as relações dos mosquitos locais com o homem, intervirá, então, num sentido desfavoravel, provocando a rúptura do equilibrio biológico protetor. Pódem-se dar diferentes exemplos dessas complexas condições de equilibrio e desiquilibrio biológico anofelinico, das quais depende, em última analise, a proteção humana.

\section{O FATOR ANIMAL E O EQUILIBRIO ZOOTROFICO ANOFELINICO}

Sabe-se hoje em dia que a introdução do fatôr animal, é susceptivel de influênciar profundamente a condição local do estado palustre. O desvio exercido pelos animais sôbre os mosquitos, póde, reduzindo ao minimo os contactos do anofelino com o homem, fazer alcançar un estado de proteção anti-palúdica mais ou menos completo. $\mathrm{O}$ valor relativo dêsse estado de proteção humana aparece, em primeiro lugar, como

(1) Tradução do artigo: Les équilibres biologiques dans l'Étiologie du paludisme. 
subordinado à uma satisfação alimentar regulada dos anofelinos, à custa dos animais. Si a população dos mosquitos locais, encontra um campo largo e constante para satisfazer sua necessidade de sangue, à custa de animais, a contribuição exigida ao homem para alimentar os mosquitos será naturalmente, ao menos em principio, bastante reduzida. A proteção humana, portanto, será tributaria daquilo que eu, (em 1921 etc.,) chamei equilibrio zootrófico; quer dizer, equilibrio biológico que assegura a alimentação normal dos mosquitos à custa dos animais. Êsse estado de equilibrio zootrófico depende, antes de tudo, da abundancia relativa de animais accessiveis à população dos mosquitos. Si o rebanho fôr bastante numeroso e colocado em condições de ataque favoraveis ao mosquito, o desvío protetor poderá ser completo; porém, si fôr insuficiente, uma parte mais ou menos grande dos anofelinos locais procurará o homem,_sendo que relações perigosas para o mesmo poderão advir.

Por um lado a relativa abundancia dos mosquitos, por outro a dos animais domesticos estabulados, representam, portanto, as duas variantes principais, susceptiveis de influênciar grandemente o equilibrio zootrófico, do qual, finalmente, depende a proteção humana.

\section{INFLUENCIA DA EXTENSÃO DAS SUPERFICIES DE ÁGUA NO ESTABELECIMENTO DE CONDIÇÕES PARA O EQUILIBRIO ZOOTROFICO}

Como por outro lado, porém, a abundancia relativa dos mosquitos está, na maior parte, condicionada ao numero e à extensão das superficies liquidas propicias ao desenvolvimento das larvas, póde-se compreender que a estabilisação dos fócos por medidas de controle apropriadas, desempenhe tambem um papel fundamental no estabelecimento do equilibrio visado.

Quer o numero de animais que desvia para si o ataque dos anofelinos seja reduzido, quer os fócos larvários aumentem de extensão, em ambos os casos verificaremos uma rúptura do equilibrio biológico protetor, que poderá influir gravemente sôbre o estado palustre.

Muitos exemplos dêsse fenomeno pódem ser citados, e, êle é sobretudo manifesto, em casos onde se vêm populações anofelinicas, normalmente pouco perigósas em virtude do seu contacto básico com os animais, passarem às fileiras de vetôres palustres efetivos.

$\mathrm{Na}$ Indochina, por exemplo, as populações do $\mathrm{A}$. hycarnus sinensis, são geralmente consideradas como mais ou menos fóra de causa na transmissão palustre local. Entretanto, em certas circunstancias, aquele anófeles póde tornar-se vêtor e, entre as causas que os observadores locais revelam como determinantes do fenomeno, a multiplicação particular do mosquito em conséquencia de uma multiplicidade anormal de seus fócos, é certamente a principal. Assim como K. $\mathrm{Hu}$ e C. Toumanoff, na China (Shangai 1936), H. Gaschen e Marneffe, em Tonkim (Haïduong) (1936), constataram o fato. Este liga-se às numerosas constatações efetuadas na Europa sôbre o A. maculipennis, no mesmo sentido.

\section{INFLUENCIA DA ORIENTAÇÃO TROFICA ANOFELINICA SÔBRE AS CONDIÇÕES DO EQUILIBRIO ZOOTROFICO}

Entretanto, o problema do equilibrio zootrófico de uma população anofelinica; não deve apenas ser julgado segundo a relação existente entre o numero relativo dos.mosquitos e o dos animais protetores;; é igualmente necessário considerar a adatação relativa das espécies anofelinicas locais aos mesmos animais. Segundo a maior ou menor seleção da orientação trófica no sentido da zoofilía, o papel protetor dos animais oferecidos aos mosquitos será de maior ou de menor eficácia. 
Sabe-se, com efeito, que em conjunto, as condições de paludismo são largamente influênciadas pela orientação dos típos anofelinicos locais, seja para a antropofilía, seja para a zoofilía. Onde predominam os típos de orientação francamente zoofila como na Indochina, A. Vagus, A. sinensis, ou na Europa os biotípos messeae, melanoon, atroparvus, o paludismo é geralmente de um pouco vulto, relativamente às regiões onde dominam os típos antropófilos (A. minimus no Extremo. Oriente, A. maculipennis. labranchiae na Europa, na Africa do Norte; etc.).

No entanto, o fato não é absoluto e conhecem-se muitos exemplos de persistencia do paludismo, em regiões povoadas por anofelinos de reação tröfica dominante. Na Europa Septentrional e Central, o paludismo se mantém, tanto na Espanha e em Portugal como na Costa Holandêsa, nas zonas de atroparvus, na Rumania, na Hungria, na Suécia, etc., em regiốs povoadas pelo biotípo messeae.

$E^{\prime}$ aqui que os fenomenos biológicos de naturezas diversas pódem intervir, para falsear o equilibrio trófico normal da fauna anofelinica, mantendo entre $o$ homem e os mosquitos um contacto suficiente; parx determinar a persistencia do paludismo.

Efetivamente, -não são apenas as variações do numero da população anofelinica que são susceptiveis de perturbar o equilibrio da proteção humana; qualquer perturbação nas condições fisiológicas habituais dos mosquitos, póde traduzir-se por uma alteração nos seus trofismos e na. sua conduta agressiva, capaz de influir sôbre as possibilidades de transmissão do paludismo.

Examinemos algumas das causas naturais, plausiveis de perturbar os habitos dos mosquitos, portanto, susceptiveis de romper o equilibrio biológico em detrimento do homem.

\section{INFLUENCIA DAS MODIFICAÇŐES FISIOLOGICAS HIBERNAIS SOBRE A CONDUTA TROFICA DOS MOSQUITOS}

As maravilhosas pesquísas realizadas há uma dezena de anos nos Países Baixos, por N. H. Swellengrebel e seus colaboradores, bem mostraram a influência exercida pelas mudanças fisiológicas hibernais sôbre o comportamento do atroparvus e a transmissão local do impaludismo. As pacientes pesquísas dos autores em questão, feitas comparativamente sôbre os dois típos biológicos locais do anófeles maculipennis, o atroparvus e o messeae, acentuaram que a persistencia do paludismo na costa da Holanda, está, antes de tudo, ligada à chegada outonal de uma perturbação fisiológica fundamental do atroparvus, perturbação sôbre a qual eu, desde 1923, tenho chamado a atenção. Esta perturbação consiste na supressão do rítmo habitual de nutrição, que subordina o crescimento dos óvulos e a postura, à digestão da refeição sanguinea. E' a discordancia gonotrófica de Swellengrebel, ou a arritmía trofogenética, que aqui proveca a rúptura do equilibrio biológico habitual. Pelo outono, efetivamente, se observa uma mudança radical no rítmo reprodutor normal do mosquito em questão. As fêmeas, chamadas a hibernar, sofrem uma paralisação particular no desenvolvimento dos seus óvulos, apesar de refeições. sanguineas mesmo repetidas. Sedentarisam-se nos locais que ocupam, deixando nas habitações humanas, de obedecer à corrente de desvio zootrófico, que no verão, arrasta-às para os estabulos.

A aptidão hemofágica sendo conservada emquanto que a aptidão reprodutora encontra-se temporariamente suspensa, esșas fêmeas picam, a pequenos intervalos, os hospedeiros que estiverem ao seu alcance. Nas. habitações humanas onde se encontram portadores latentes da infecção paludica, elas tornam-se os agentes da dispersão familiar, cuja importancia: epidemiológica os autores dos Países Baixos tão bem traduziram. 
Para outros biotípos de anofelinos como o biotípo messeae do A. maculipennis, o periodo de inverno é geralmente considerado como um periodo de quási completa interrupção da atividade hemofágica, durante o qual os mosquitos perdem a possibilidade de qualquer intervenção patogenica. Porém, si esta referencia é exata no que se refere às fêmeas pertencentes àquele típo racial, quando já adquiriram a carga de gordura que as faz passar ao verdadeiro estado de hibernantes, segundo Grassi, isto certamente não acontece durante as primeiras semanas que seguem à eclosão. Efetivamente, observei com M. Treillard (1936); que o desenvolvimento das reservas de gordura nessas fêmeas, sobrevém em prosseguimento à repetidas refeições de sangue, durante as quais as hibernantes do típo messeae se conduzem sensivelmente da mesma. maneira que as do atroparvus. Acham-se aptas a multiplicar as picadas, sem que com isto os seus óvulos se desenvolvam e sem que sejam levadas, em consequencia, para os expelir, a se afastarem dos locais e dos hospedeiros que exploram. Quando se trata de habitações humanas, teoricamente nada se opõe a que os mosquitos, tendo penetrado nos locais para se alimentarem, contraiam em tais condições, relações favoraveis à transmissão palustre.

V:ê-se por êsses exemplos quantas perturbações pódem ser causadas ao equilibrio relativo de proteção humana, por uma modificação fisiológica profunda, sobrevinda nos mosquitos. Os fenomenos hibernais e estivais susceptiveis de oferecer, nos diferentes típos anofelinicos, uma tão acentuada escala de variações biológicas possiveis, devem ser seguramente responsaveis, aliás grandemente responsaveis, pelas perturbações biológicas variadas que concernem ao estado palustre. A reativação metabólica que aféta muitas espécies após o periodo hibernal ou estival, é de natureza a modificar inteiramente o papel vêtor normal, exacerbando nas fêmeas as necessidades de sangue. Não se póde sinão desejar que os malariologistas penetrem ainda mais no estudo, até agora insuficientemente compreendido, das modificações de habitos que provocam os rítmos de inatividade (aștenóbiose), nos diferentes anofelinos.

Os fenomenos de repouso de inverno ou verão, que afetam numerosas espécies, são geralmente encarados como diretamente ligados às simples ações da temperatura exterior. Um estudo mais profundo mostra que são muito poucos os casos em que se trata realmente de mudanças mais complexas, de natureza rítmica ou cíclica, sobrevindas espontaneamente nas necessidades fisiológicas dos mosquitos. E essas perturbações, a epidemiologia deve considerar, em grande parte, como capazes de exercer uma influência mais ou menos desfavoravel, sob o ponto de vista humano, no equilibrio habitual dos fatôres anti-paludicos.

\section{INFLUENCIA DA ALIMENTAÇÃO LARVARIA SOBRE O COMPORTAMENTO TROFICO ANOFELINICO}

Um outro fenomeno ao qual até agora pouca atenção se conferiu, na interpretação das perturbações biológicas susceptiveis de refletir sôbre o equilibrio das condições de paludismo, está nas mudanças sobrevindas na alimentação das larvas dos anofelinos.

Pensa-se geralmente, que sómente as condições de alimentação sanguinea oferecidas aos anófeles, entram em linha de conta na agressividade relativa que as fêmeas manifestam para com o homem. Isto, porém, é um ponto de vista assáz limitado, e, nós demonstramos, especialmente com M. Treillard, (1934), que as condições da alimentação larvaria, influem igualmente sôbre o comportamento dos mosquitos alados. As fêmeas do maculipennis, saídas de larvas pobremente nutridas de substancias protéicas, são mais agressivas e picam mais cêdo do que aquelas que tiveram uma alimentação protéica mais acentuada. O fenomeno é da mesma natu- 
reza, embóra menos marcado, que o observado com o culex pipiens, da raça autogena, quandò é mal nutrido em seu estado larvario. Há bases para supôr que as modificações sofridas pela alimentação larvaria, no decurso de modificações periódicas ou não do régimem das águas, não deixam de influir sôbre as necessidades de sangue relativas dos anófeles locais e, portanto, sôbre o equilibrio biológico do qual depende a proteção humana.

Constatei por exemplo, (1932), em uma localidade da Vendéa, onde minhas observações proseguem já há muitos anos, que a agressividade dos anófeles locais da raça atroparvus, varía notadamente para uma mesma época, segundo os anos. Certos anos de verão chuvoso, deixam observar uma agressividade para o homem muito mais pronunciada do que a normal. Esșes periodos coincidem não sómente com a abundancia maior dos mosquitos, mas tambem com a invasão, pela população anofelinica, de novos fócos larvarios constituidos pelas póças de inundação. Os fócos habituais são então desprezados por outros, que.. contém elementos planktonicos novos;; eu atribuí a tal mudança das condições alimentares, a agressividade aumentada dos anófeles.

Essas observações me fazem concordar inteiramente com Gil Collado, (1937), quando êle tende a considerar que as circunstancias desfavoraveis ao desenvolvimento larvario anofelinico na Espanha, não deixam de exercer uma influência favoravel sôbre o desenvolvimento local do paludismo: mosquitos mal alimentados em estado larvario, pódem ser incontestavelmente mais perigósos, em razão de suas necessidades de sangue acrescidas, do que mosquitos aos quais uma alimentação larvaria rica favoreceu com a elaboração de importantes reservas nutritivas. As fêmeas de anofelinos largamente providas de recursos protéicos ou lecitinicos, picarão mais tarde e-chegarão à póstura, após uma refeição de sangue minima. É fácil conceber que sua atividade hemofágica perigósa fique assim notavelmente reduzida, mesmo quando se trata de biotípos fundamentalmente orientados para a zoofilía.

Tenho insistido muitas vêses sôbre o fato das manifestações de orientação trófica dos anofelinos, não poderem ser julgạdas sinão por um equilibrio normal de nutrição sanguinea. Sob a influência do jejum, as fêmeas dos anófeles vêm exacerbarem-se suas necessidades de sangue, e os hospedeiros habitualmente pouco procurados, pódem então ser atacados com insistencia. Sob a influência de condições alinentares larvarias deficientes, poder-se-á, portanto, vêr espécies ou raças comumente pouco inclinadas ao homem, como os representantes do biotípo messeae, tornarem-se exploradoras perigósas das habitações humanas. Assim, se póde explicar que em inumeras regiões da Europa Central e Septentrional onde o típo de anofelino zoofilo predomina, un certo estado palustre se possa manter.

Não será tambem necessário considerar aqui o fenomeno que denominei (1933) "Memória trófica", ou tendencia, nos anofelinos que acidentalmente se alimentaram num hospedeiro pouco habitual, a vóltar ao mesmo? Esses fenomenos que assinalei e estudei no decorrer de experiencias de laboratorio, não deram, até agora, origem a experiencias e constatações seguidas. Insisto aqui sôbre a necessidade de proseguir, neste campos de idéias, em novas pesquisas. O fenomeno das "casas palúdicas" particularmente, em certas circunstancias talvez não seja extranho ao fato da "memória trófica", que leva certos anófeles acidentalmente alimentados em determinados hospedeiros humanos, a voltarem ao mesmo contacto. 


\section{PERTURBAÇÕES DO COMPORTAMENTO TRÓFICO LIGADAS AO HIBRIDISMO (*)}

De um modo geral, qualquer perturbação nas condições biológicas doj anófeles, si fôr de natureza a provocar uma recrudescência brusca de sua atividade metabólica e de sua aptidão hemofágica, será susceptivel de träduzir-se, quanto ao ponto de vista humano, por uma recrudescência possivel do estado palúdico.

Entre essas perturbações perigósas, cuja biologia anti-palúdica deve entrar em consideração, convém igualmente citar os entre-cruzamentos naturais entre as variedades locais ou sub-espécies fisiológicas dos anófeles. Sabe-se que os estudos modernos tendem a fazer resaltar cada vez mais, a frequencia de diferenciação em raças ou em biotípos diversos de uma determinada espécie culicidiana, de grande dispersão geográfica: No que se refere ao A. maculipennis, já são numerosos os biotípos da espécie que foi possivel diferenciar no decorrer dêsses últimos anos, depois que Falleroni soube despertar o interesse sôbre as modificações morfológicas dos óvos caracteristicos dos diferentes biotípos. Em que proporção os diferentes típos raciais que frequentemente coexistem nas mesmas zonas geográficas, são susceptiveis de misturar-se entre si, é o que até agora se tem tornado dificil de averiguar com precisão. As experiencias de laboratorio feitas em diversos pontos, na Holanda, na Italia, na França, sôbre - mesmo assunto - o hibrídismo - mostraram que emquanto entre certos biotípos se puderam realisar facilmente, fracassaram entre outros. Especialmente pennis atroparvus e A. maculipennis messeae, não poude até agora ser experimentalmente constatado como fenomeno positivo, por A. de Buck e N. H. Swellengrebel (1937).

Entretanto, as observações e experiencias que realisei com meus colaboradores, J. Colas, Belcour e M. Treillard (1937), demonstraram que na natureza, tais hibrídismos seguramente não são impossiveis para os dois biotípos anofelinicos.

Os hibridos obtidos no laboratorio entre as raças ou espécies de culicidios, sobretudo como- constatei (1933) entre os dois biotípos europeus do Culex Pipiens, dão mostrạs de uma agressividade para o homem, frequentemente muito acrescida. E para mim um motivo de supôr que as modificações fisiológicas resultantes da interferencia genética dás formas anofelinicas, representam fatôres certos de desiquilibrio biológico, susceptiveis de exercerem, em certas circunstancias, um reflexo sôbre o estado palustre.

Limitarei a êsses os exemplos de desiquilibrio fisiológico anofelinico, plausiveis de entrarem em linha de conta nas cogitações dos malariologistas. Ainda que me sejam suficientes para insistir aqui sôbre a necessidade de penetrar cada vez mais estreitamente, na fisiologia dos anófeles, até o presente momento ainda insuficientementte conhecida. Sobretudo, formularei um voto para que se esforcem em melhor definir todas as causas biológicas capazes de reagir sôbre a agressividade e as relações das populações anofelinicas com o homem, e assim, sôbre as condições do paludismo.

(*) Acta Conventus Tertii de Tropicis Atque Malariae Morbis, Pars II Amsterdam, 1937, pgs. 130-138. 